\title{
The behavioural characteristics of local authority home residents referred to a geriatric psychiatry
} service

\author{
G. MASTERTON, E. M. HOLLOWAY, AND G. C. TIMBURY \\ From Gartnavel Royal Hospital, Glasgow
}

SUMMARY With increasing demands upon a geriatric psychiatry service, the priorities for day care and long-term hospital care have had to be re-examined. As a result, old people already in local $\vec{\circ}$ authority residential care are receiving lower priority than those still in the community. In this study we suggest that certain behavioural characteristics and, in particular, incontinence, may present the $\vec{\omega}$ caring staff of residential homes with special difficulties. We conclude that adequate assessment is essential to ensure that residents are suited to the level of facilities supplied.

Because referrals to the geriatric psychiatry services of Gartnavel Royal Hospital have increased, the hospital's policies have had to be modified within available limits of staff and finance. A waiting list was originally operated to determine admission to long-stay inpatient care, but because of the pressure on the service, admission of patients now has to be decided by factors other than the length of time spent on the waiting list. The kind of considerations that have to be taken into account when allocating a bed include the type or severity of the patient's behavioural disability, the availability of local community support, and, in particular, the attitudes and coping abilities of the immediate family of the patient and the stresses upon them.

This has led to a conceptual change of emphasis from 'waiting list' to 'at risk register'. Another development is that people already in some form of residential care are generally regarded as having low priority for admission. The mean duration on the 'at risk register' is therefore somewhat longer for patients living in residential homes -16 months compared with 11 months for those remaining at home; and, in practice, admission of a resident from a home is mainly determined by the availability of a suitable patient with whom an exchange can be made.

The geriatric psychiatry day hospital has now been developed to play a major role in providing support for the patient living at home until a bed becomes available in the psychogeriatric wards. ${ }^{1}$ However, once again it is the people in the local authority and voluntary residential homes who receive the thin end of the hospital resources wedge. Seventy per cent of those on our 'at risk register' who live at home atten the day hospital, but the comparable figure for those $N$ in residential care is only $37 \%$.

The residential homes are an important and essential part of the management of the elderly $\subseteq$ mentally infirm. Two recent Scottish studies of loc authority homes have rcported that about $30 \%$ of $\overrightarrow{0}$ their population show clear evidence of dementia $\infty$ which is about seven times the prevalence in the community (Masterton $e \mathrm{al}^{2}$ and Carstairs V, 1979; Clackmannanshire Study, written communication). This concentration is reflected in the patients on our geriatric psychiatry 'at risk register': $12 \%$ are residents in the local authority homes which $\triangle$ accommodate approximately $1 \frac{1}{2} \%$ of the catchment $\overrightarrow{\overline{0}}$ area's geriatric population.

It is reasonable to assume that referral for geriatric psychiatry, which in this study always resulted in subsequent placement on the 'at risk register', stems from a failure of the caring staff to cope effectively on $\stackrel{\rho}{子}$ their own with the resident's behaviour. In this study some of the clinical characteristics and behavioural traits of the 22 residents referred and currently on the $\stackrel{\rho}{\rho}$ register are described, and the implications of identifying their behavioural problems are discussed. 을

\section{Subjects and method}

As every home had at least one resident on the 'at risk register', all 11 local authority homes within the $\mathrm{Gr}$ catchment area of Gartnavel Royal Hospital were $N$ included in the study. Of the total population of $404, N$ 385 residents $(95 \%)$ were included. The 19 excluded cases were on other waiting lists. 
Table 1 Comparison of the characteristics of local authority home residents referred to a geriatric psychiatry service with those of residents not on any waiting list

\begin{tabular}{|c|c|c|c|}
\hline Characteristics & $\begin{array}{l}\text { Referrals } \\
(n=22)\end{array}$ & $\begin{array}{l}\text { Residents not on } \\
\text { any waiting list } \\
(n=363)\end{array}$ & $\begin{array}{l}\text { Student's } \\
\text { t test }\end{array}$ \\
\hline Age (years) & $79 \cdot 27+1-5 \cdot 62$ & $79 \cdot 45+/-9.34$ & $0 \cdot 136 \mathrm{NS}$ \\
\hline Time in home (years) & $2.05+1-1.43$ & $3.43+1-3.90$ & $3 \cdot 689^{* * *}$ \\
\hline \multicolumn{4}{|l|}{ Sex } \\
\hline Males & 2 & 114 & \\
\hline Females & 20 & 249 & $\chi^{2}=4 \cdot 10^{*}$ \\
\hline \multicolumn{4}{|l|}{ BEHAVIOURAL DISABILITY } \\
\hline SSGRS total & $23 \cdot 32+/-6 \cdot 31$ & $12 \cdot 32+1-7 \cdot 32$ & $6.984^{* * *}$ \\
\hline Physical disability & $8.09+1-2.62$ & $4 \cdot 15+1-2 \cdot 83$ & $6 \cdot 660^{* * *}$ \\
\hline Apathy or inactivity & $8 \cdot 50+/-1 \cdot 41$ & $5 \cdot 30+1-2 \cdot 71$ & $9 \cdot 647^{* * *}$ \\
\hline Communication difficulty & $1.73+1-1.67$ & $0.48+1-0.94$ & $3.466^{* * *}$ \\
\hline Socially disruptive behaviour & $5 \cdot 09+1-2 \cdot 74$ & $2 \cdot 38+1-2 \cdot 46$ & $4 \cdot 396^{* * *}$ \\
\hline
\end{tabular}

*P $<0.05$

** $\mathrm{P}<0.01$

$* * * P<001$

The senior member of staff in the home provided an assessment of behaviour disabilities for each resident using the Shortened Stockton Geriatric Rating Scale (SSGRS). ${ }^{3}$ The SSGRS consists of 18 items with proven high interrater reliability which are combined to measure four aspects of impairment-physical disability; apathy or inactivity; communication difficulties; and socially disruptive behaviour. The high correlations between the subscores and total score of the Stockton scales make it possible to obtain a detailed profile of behavioural assets and deficiencies which is a valid measure for comparing between and within groups.

The study consisted of a comparison of the 22 residents on the 'at risk register' with three groups of co-residents. Initially the characteristics of the group of subjects were compared with those of the 363 residents not on any waiting list. Then each subject's behavioural profile was compared with that of the two residents from the same home whose total Stockton score most nearly approximated to his or her own. This match was satisfactory $(\mathrm{df}=64$, Student's $t$ test $=1 \cdot 54$ NS).

Finally, each subject's behavioural profile was compared with that of two residents from the same home who were matched for sex and age. This procedure was necessary to take into account the known positive correlation between the SSGRS and advancing age. As well as a highly satisfactory match for age ( $\mathrm{df}=64$, Student's $t$ test $=0.19 \mathrm{NS})$, it was coincidentally discovered that duration in the home had also been controlled ( $\mathrm{df}=64$, Student's $t$ test $=0.80 \mathrm{NS}$ ).

\section{Results}

Behavioural disabilities, measured by the SSGRS total score and individual factor scores, were found to a highly significantly greater degree among the subjects when compared with residents not on any waiting list. Women were significantly over-represented in the referred group and while the mean ages were almost identical, referral was highly significantly associated with a shorter mean duration in the home (Table 1).

An analysis of the individual items of behaviour demonstrated that incontinence and an inability to communicate were present to a significantly greater degree among the subjects when compared with residents matched for overall level of disability. There were no other significant differences between the groups (Table 2).

Table 2 Stockton geriatric rating scale items of behaviour: referrals versus a group matched for total level of behavioural disturbance

\begin{tabular}{lllc}
\hline Question & Factor & Item & $\chi^{2}$ \\
\hline 2 & PD & Incontinence & $13 \cdot 66^{* *}$ \\
8 & CD & Cannot communicate & $6 \cdot 17^{*}$ \\
\hline df $=2$ & $* P<0.05$ & CD $=$ Communication difficulty
\end{tabular}

Comparing the subjects with age- and sex-matched residents revealed significant differences between the groups in 12 of the 18 items (Table 3). For nine items the difference was significant at the $1 \%$ level and for five items at the $0 \cdot 1 \%$ level. The top three items of behaviour were all included in the physical disability factor and, once again, incontinence was clearly the single most important behavioural trait differentiating subjects from controls.

\section{Discussion}

The characteristics of local authority home residents who have been placed on a geriatric psychiatry 'at risk register' have been identified. By comparing the 
Table 3 Stockton geriatric rating scale items of behaviour: referrals versus a group matched for age, sex, and length of stay in the home

\begin{tabular}{|c|c|c|c|}
\hline Question & Factor & Item & $x^{2}$ \\
\hline 2 & PD & Incontinence & $37 \cdot 89^{* * *}$ \\
\hline 12 & PD & Untidy appearance & $24 \cdot 82^{* * *}$ \\
\hline 11 & PD & Confused in the home & $22 \cdot 25^{* * *}$ \\
\hline 13 & $\mathrm{CD}$ & Cannot understand & $20 \cdot 00^{* * *}$ \\
\hline 5 & SD & $\begin{array}{l}\text { Objectionable behaviour } \\
\text { at night }\end{array}$ & $14 \cdot 60^{* * *}$ \\
\hline 18 & AI & Not amenable to suggestion & $13 \cdot 72^{* *}$ \\
\hline 8 & $\mathrm{CD}$ & Cannot communicate & $12 \cdot 95^{* *}$ \\
\hline 17 & SD & Sleep disturbance & $12 \cdot 65^{* *}$ \\
\hline 3 & PD & Help required to bath or dress & $11 \cdot 80^{* *}$ \\
\hline 10 & PD & Gets lost outside & $8 \cdot 07^{*}$ \\
\hline 15 & AI & Cannot keep self occupied & $7 \cdot 46^{*}$ \\
\hline 6 & SD & Hoarding trivia & $6 \cdot 26^{*}$ \\
\hline 16 & AI & Poor relationship with others & $5 \cdot 27$ \\
\hline 14 & AI & Does not help in home & $4 \cdot 88$ \\
\hline 7 & PD & Help required to walk & 2.97 \\
\hline 1 & SD & Falsely accuses others & 2.49 \\
\hline 9 & AI & In bed during the day & $1 \cdot 79$ \\
\hline \multirow[t]{2}{*}{4} & \multirow[t]{2}{*}{ SD } & \multirow{2}{*}{$\begin{array}{l}\text { Objectionable behaviour } \\
\text { during the day }\end{array}$} & \\
\hline & & & 0.76 \\
\hline $\begin{array}{l}\mathbf{d t}=\angle \\
\mathrm{PD}=\mathrm{Ph} \\
\mathrm{SD}=\mathrm{So}\end{array}$ & $\begin{array}{l}* \mathbf{P} \\
\text { sabilit } \\
\text { rupti }\end{array}$ & $\begin{array}{l}* * \mathbf{P}<0.01 \\
C D=\text { Communicat } \\
\quad \text { AI = Apathy }\end{array}$ & $\begin{array}{l}P<0 \cdot 001 \\
\text { difículty } \\
\text { inactivity }\end{array}$ \\
\hline
\end{tabular}

subjects with the remainder of the population of the residential homes, after excluding those on geriatric medicine waiting lists, it was demonstrated that female sex and a shorter duration in the homes were significant factors associated with presence on the 'at risk register', and that age had a negligible influence. Higher levels of all types of behavioural disability were shown by the subjects.

After controlling for total behavioural disability, two items of behaviour, incontinence and an inability to communicate, significantly differentiated subjects from controls.

When a similar analysis was carried out, this time with a control group matched for age, sex, and duration in the home, a further 10 items of behaviour significantly differentiated between the groups.

As these residents had been on our geriatric psychiatry 'at risk register' for a mean duration of 16 months at the time of the study, the results are not an identification of the behavioural difficulties which had led the homes to seek psychiatric help. Deterioration due to progressing dementia and intervention through day hospital attendance and drug treatment in half the cases render this conclusion false. Nevertheless the findings of this study merit consideration.

The observation in our earlier study, ${ }^{2}$ that levels of socially disruptive behaviour were higher in local authority homes than in three other types of residential accommodation for the elderly, led us to several conjectures, one of which was that the staff had poor tolerance of these aspects of behaviour. If this was so, items relating to socially disruptive behaviour might have been expected to rank highly in the disabilities of residents referred to the geriatric psychiatry service. However, physical disabilities rank higher, among those residents referred, than the main factors of social disturbance which relate to disturbance at night (Table 3).

The demonstration that incontinence not only best differentiates subjects from age- and sex-matched residents, but also from residents whose overall level of behavioural disability is equally severe, suggests that this problem, above all others considered, creates difficulty for the staff. Its importance has been mentioned elsewhere ${ }^{4}$ and it may be concluded that the presence of severely incontinent old people in residential homes is undesirable.

As the projected increase in the number of elderly people in the population develops, ${ }^{5}$ social work departments have noted an increase in the age and dependency of elderly people coming into their care $^{6}$ : in a recent study a rise in the mean level of behavioural disabilities in local authority homes was shown when the 1977 value was compared with that of $1976 .^{7}$ Some of the difficulties, however, are undoubtedly due to the misplacement not only of demented and incontinent old people better suited t $\mathrm{P}$ hospital ${ }^{8}$ but also of more independent old people 응 who would be better placed in a less dependen setting such as sheltered housing. ${ }^{9}$ These problemso which are avoidable, result from an absence of more detailed criteria for admis ion to residential homes. ${ }^{10}$

Using the SSGRS, Pattie and Gilleard found that cut-off value of 7 on the total score would result in the admission of $81 \%$ of the residents with high adjustment/minimal deterioration and the correct identification of $71 \%$ of those with poor adjustment/rapid deterioration. An identical cut-off would exclude $72.4 \%$ of all the subjects who took part in this study and $82 \%$ of the 33 residents who had been in the homes less than three months. While the choice lies between two systems of care, hospital and local authority home, this criterion seems too stringent, but the creation of an additional, intermediate grade of accommodation could well make it more useful.

It is suggested in this study that the overall level of behavioural disability may be of less importance than the presence or absence of certain key disabilities. The development of reliable assessment schedules should aim to identify these characteristics.

To provide an efficient service for the elderly in the community, it is recognised that different types of residential establishments are required. However, such provision is pointless unless adequate precautions are taken to ensure that residents are suited, and remain suited, to the level of facilities, trained staff, and liaison services supplied. 
We thank Dr. J. Greene, principal clinical psychologist, Gartnavel Royal Hospital; the district managers and supportive services officers of the Clydebank, Dumbarton, and Glasgow West Districts of Strathclyde Social Work Department; and in particular the staff in the homes.

Reprints from Dr. G. Masterton, Gartnavel Royal Hospital, 1055, Great Western Road, Glasgow G12 0XH.

\section{References}

${ }^{1}$ Greene JG, Timbury GC. A geriatric psychiatry day hospital service: A five-year review. Age Ageing 1979; 8: 49-53.

${ }^{2}$ Masterton G, Holloway EM, Timbury GC. The prevalence of organic cerebral impairment and behavioural problems within local authority homes for the elderly. Age Ageing 1979; 8: 226-30.
${ }^{3}$ Gilleard CJ, Pattie AH. The Stockton Geriatric Rating Scale: a shortened version with British normative data. Br J Psychiatry 1977; 131: 90-4.

${ }^{4}$ Lowther CP, MacLeod HM. Admissions to a welfare home. Health Bull 1974; 32: 14-18.

${ }^{5}$ Central Statistical Office. Population Projections 1974-2014. London: HMSO, 1976.

${ }^{6}$ Department of Health and Social Security and Welsh Office. Residential Homes for the Elderly: Arrangements for Health Care. A memorandum of guidance. London: DHSS, 1977.

${ }^{7}$ Wilkin D, Mashiah T, Jolley DJ. Changes in behavioural characteristics of elderly populations of local authority homes and long-stay hospital wards, 1976-7. Br Med J 1978; ii: $1274-6$.

${ }^{8}$ Smith RG, Lowther CP. Follow-up study of two hundred admissions to a residential home. Age Ageing 1976; 5: 176-80.

${ }^{9}$ Coleman PG. Social gerontology in England, Wales, and Scotland. A review of recent and current research. Gerontologist 1975; 15: 219-29.

${ }^{10}$ Pattie AH, Gilleard CJ. Admission and adjustment of residents in homes for the elderly. $J$ Epidemiol Community Health 1978; 32: 212-4. 